\title{
EBSD Analysis of Deformed and Partially Recrystallized Microstructures in ECAE- Processed Copper
}

Mishin, Oleg; Bowen, Jacob R.; Godfrey, A.

Published in:

Materials Science Forum

Link to article, DOI:

10.4028/www.scientific.net/MSF.715-716.825

Publication date:

2012

Document Version

Early version, also known as pre-print

Link back to DTU Orbit

Citation (APA):

Mishin, O., Bowen, J. R., \& Godfrey, A. (2012). EBSD Analysis of Deformed and Partially Recrystallized Microstructures in ECAE-Processed Copper. Materials Science Forum, 715-716, 825-830.

https://doi.org/10.4028/www.scientific.net/MSF.715-716.825

\section{General rights}

Copyright and moral rights for the publications made accessible in the public portal are retained by the authors and/or other copyright owners and it is a condition of accessing publications that users recognise and abide by the legal requirements associated with these rights.

- Users may download and print one copy of any publication from the public portal for the purpose of private study or research.

- You may not further distribute the material or use it for any profit-making activity or commercial gain

- You may freely distribute the URL identifying the publication in the public portal 


\title{
EBSD analysis of deformed and partially recrystallized microstructures in ECAE-processed copper
}

\author{
O.V. Mishin ${ }^{1, a}$, J.R. Bowen ${ }^{2, b}$ and A. Godfrey ${ }^{3, c}$ \\ ${ }^{1}$ Center for Fundamental Research: Metal Structures in Four Dimensions, Materials Research \\ Division, Risø National Laboratory for Sustainable Energy, Technical University of Denmark, \\ DK-4000 Roskilde, Denmark \\ ${ }^{2}$ Fuel Cells and Solid State Chemistry Division, Risø National Laboratory for Sustainable Energy, \\ Technical University of Denmark, DK-4000 Roskilde, Denmark \\ ${ }^{3}$ Laboratory of Advanced Materials, Department of Materials Science and Engineering, Tsinghua \\ University, Beijing 100084, P.R. China \\ aolmi@risoe.dtu.dk, ${ }^{\mathrm{b}}$ jrbo@risoe.dtu.dk, ${ }^{\mathrm{C}}$ awgodfrey@mail.tsinghua.edu.cn
}

Keywords: copper, equal channel angular extrusion (ECAE), severe plastic deformation, partial recrystallization

\begin{abstract}
The deformed microstructure and recrystallization behavior of copper samples processed using equal channel angular extrusion (ECAE) have been investigated. The heavily deformed microstructure was found to be non-uniform through the sample thickness and to vary in a manner consistent with the non-uniform distribution of strain imposed by processing. The through-thickness heterogeneity of the deformed microstructure resulted in a different extent of recrystallization in different layers during annealing. Recrystallized grains were also observed in samples that were not annealed, but stored at room temperature, which indicates that the deformed microstructure of ECAE-processed pure copper is unstable even at room temperature. In each sample, recrystallization was found to initiate in regions containing predominantly large misorientations.
\end{abstract}

\section{Introduction}

Equal channel angular extrusion is one of the most commonly used techniques for severe plastic deformation. In many early publications, microstructures produced by ECAE have been described as homogeneous [1,2]. More detailed microstructure analysis however indicates that the ECAEdeformed materials are typically heterogeneous. The heterogeneities exist both locally and on the sample scale, e.g. from the end to the middle [3] or the top to the bottom of the billet [4]. The presence of deformation-induced heterogeneities is known to affect the progress of recrystallization and therefore should be characterized thoroughly. In our previous work [4-6], we have performed quantitative analysis of heterogeneities of the deformed and partially recrystallized microstructure in several copper samples heavily deformed by ECAE. Most important findings from these experimental studies are summarized in the present communication.

\section{Experimental}

Two copper samples (99.96\% purity) were deformed to a strain of 8 using a $90^{\circ}$ die $[5,6]$. The samples were deformed either without rotation of the billet (route A) or using sequential $90^{\circ}$ rotations between passes (route $\mathrm{Bc}$ ). This material was investigated in the as-deformed condition [5] and after eight years of room-temperature storage [6]. An additional route-A sample (copper of 99.98\% purity) was prepared by extruding a 15-mm-diameter billet of length $100 \mathrm{~mm}$ to a strain of 10 in a $120^{\circ}$ die [4]. A part of this sample was stored at $-20^{\circ} \mathrm{C}$ between sample preparation and characterization operations. Another part was annealed at $160^{\circ} \mathrm{C}$ for 2 hours. In this sample, three different depths were investigated: $1 \mathrm{~mm}$ from the top surface (the surface that passed through the inner corner of the ECAE die), along the centerline and at $0.4 \mathrm{~mm}$ from the bottom surface. These 
depths correspond to $\sim 7,50$, and $97 \%$ from the top surface, which are hereafter referred to as the top, center, and bottom of the billet, respectively.

The microstructure of the samples was investigated in the longitudinal side section that contained the extrusion direction (ED) and the normal direction (ND), see [4,5]. The EBSD technique coupled to a Zeiss Supra 35 FEGSEM was used for orientation mapping. For each sample and investigated depth, several EBSD maps were produced each covering approximately $3400 \mu \mathrm{m}^{2}$. Due to the presence of orientation noise in the data only misorientations above $2^{\circ}$ were considered in a quantitative analysis of boundary populations. The heterogeneity was analyzed using a method that is based on a partitioning of the microstructure into regions containing either predominantly high angle misorientations, referred to as high misorientation regions (HMRs), or predominantly low angle misorientations, referred to as low misorientation regions (LMRs) [4,6-8]. To obtain a LMR/HMR partitioning, a "grain reconstruction" of each ESBD data set was carried out at $5^{\circ}$. Then all detected "grains" with an area greater than $2.5 \mu \mathrm{m}^{2}$ were classified as LMRs and the remaining regions were classified as HMRs. Thus, each LMR subset consists of regions $>2.5 \mu \mathrm{m}^{2}$ where the microstructure contains boundaries with misorientation of $<5^{\circ}$. A modified approach was used for quantitative analysis of recrystallized grains (for details see [4,6]).

\section{Results and Discussion}

The microstructure from the center layer of the route-A sample deformed to a strain of 10 is shown in Fig. 1. No recrystallized grains were observed in this sample after one year of cold storage. The misorientation map (Fig. 1a) demonstrates that the microstructure consists of well-refined regions mostly subdivided by high angle boundaries (HABs) alternating with regions that contain mainly low angle boundaries (LABs). Quantitative analysis of these two types of subdivided regions is enabled through the HMR/LMR partitioning. The HMR/LMR map is given in Fig. 1b, where grey (cyan in the online version) regions are HMRs and white regions are clusters of LMRs. Following such a partitioning the area fraction and other characteristics of these regions can be analyzed separately. The same approach was applied for characterizing the microstructure in the top and bottom layers and the results are given in Table 1.

It is seen that the fraction of HABs approaches $60 \%$ in a large portion of the billet, but reduces to $\sim 50 \%$ near the volumes that have passed through the outer die corner. The HAB spacing is greater near the bottom compared to the values for the top and center layers. This type of heterogeneity is due to the non-uniform strain distribution through the billet thickness. For the same die and similar friction conditions, it was established that the applied strain was much lower in the bottom of the billet than in the center and top layers, where the applied strain was relatively uniform [3]. Therefore, the greater HAB spacing and lower fraction of HABs in the bottom are due to the lower strain in this part of the ECAE-deformed billet.

It is interesting that the LMR/HMR fractions appear to be more sensitive parameters than the fraction of HABs/LABs or the boundary spacing. Whereas the latter parameters are very similar for the top and the center of the billet (Table 1), the LMR/HMR fractions vary considerably between these layers, better reflecting the heterogeneity of the microstructure. The broad LMR bands found in the center of the deformed billet are suggested to originate from the coarse grains that were frequent in the initial microstructure in this layer [4]. It appears that some of these grains were able to resist breaking into highly misoriented volumes even after a strain of $\sim 10$. Analysis of pole figures indicated that the LMR bands represented two main ideal orientations of the predicted ECAE texture [4]. Weak ECAE textures were observed in the HMRs. 


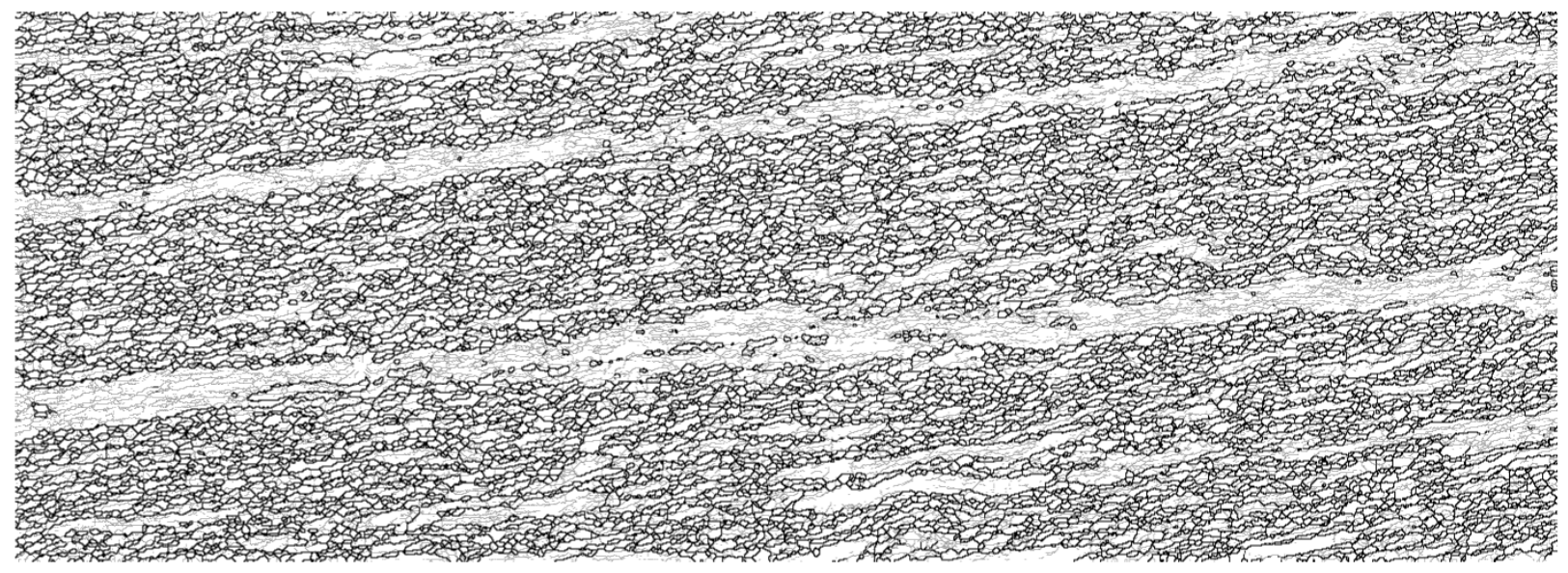

(a)

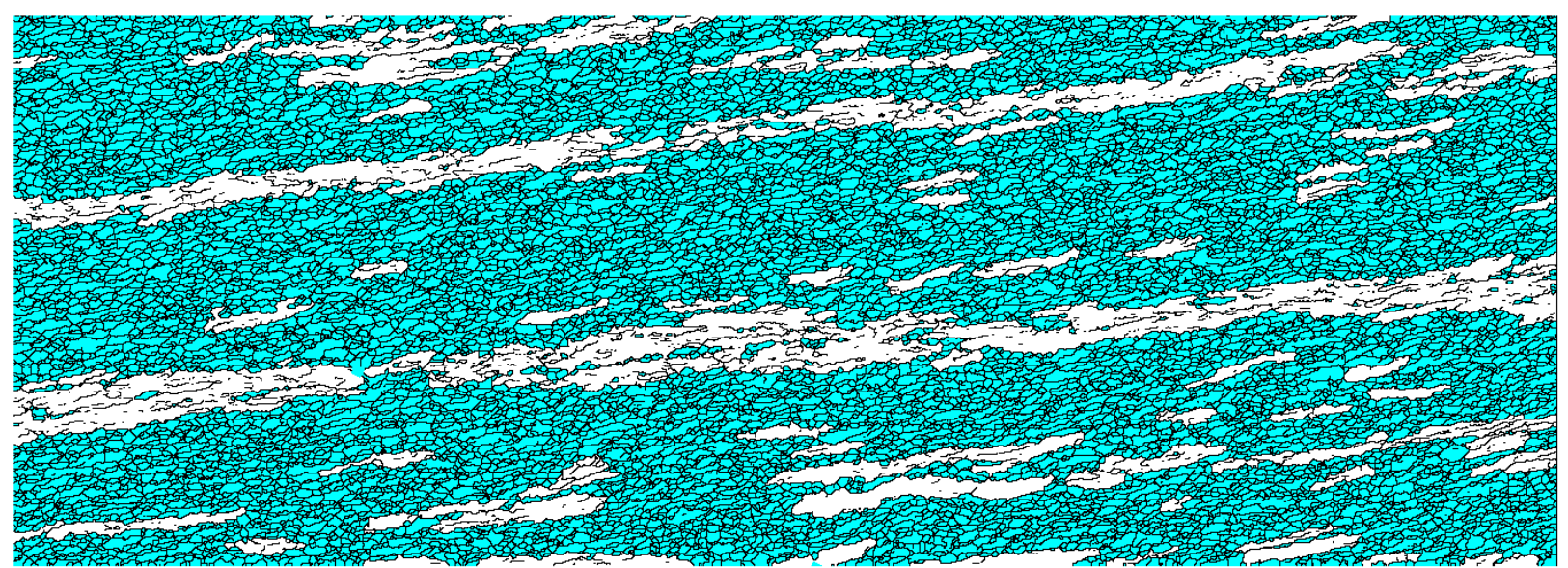

(b)

Fig. 1. EBSD maps for the center layer of the copper sample deformed to a strain of 10 using route A: (a) misorientation map; (b) LMR/HMR map. In (a) HABs $\left(>15^{\circ}\right)$ are shown in black. Misorientations 2 to $15^{\circ}$ are shown as thin grey lines. In (b) LMRs are shown in white and HMRs are grey (cyan in the online version), with misorientations of $>5^{\circ}$ shown in black.

Table 1. Microstructural characteristics in different layers of the copper sample deformed using route A ECAE to a strain of 10 .

\begin{tabular}{lcccc}
\hline Layer & $\begin{array}{c}\text { Average HAB } \\
\text { spacing [ } \mu \mathrm{m}] \\
\text { ND / ED }\end{array}$ & HAB fraction [\%] & \multicolumn{2}{c}{ Area fraction [\%] } \\
\cline { 4 - 5 } & $0.34 / 0.62$ & 57 & 87 & LMRs \\
\hline Top & $0.36 / 0.60$ & 58 & 81 & 13 \\
Center & $0.43 / 0.78$ & 51 & 72 & 19 \\
Bottom & & & & 28 \\
\hline
\end{tabular}

The high frequency of mobile boundaries and a high driving force for recrystallization make HMRs preferable sites for nucleation. Indeed, most recrystallized grains in the partially recrystallized microstructure were found inside the HMRs (see Fig. 2). Therefore, the relative loss of the HMRs during recrystallization was significant compared to that of the LMRs. Figure 3 shows that the initial fraction of the LMRs remained almost unchanged in the partially recrystallized condition, while recrystallization consumed a significant fraction of the HMRs. 


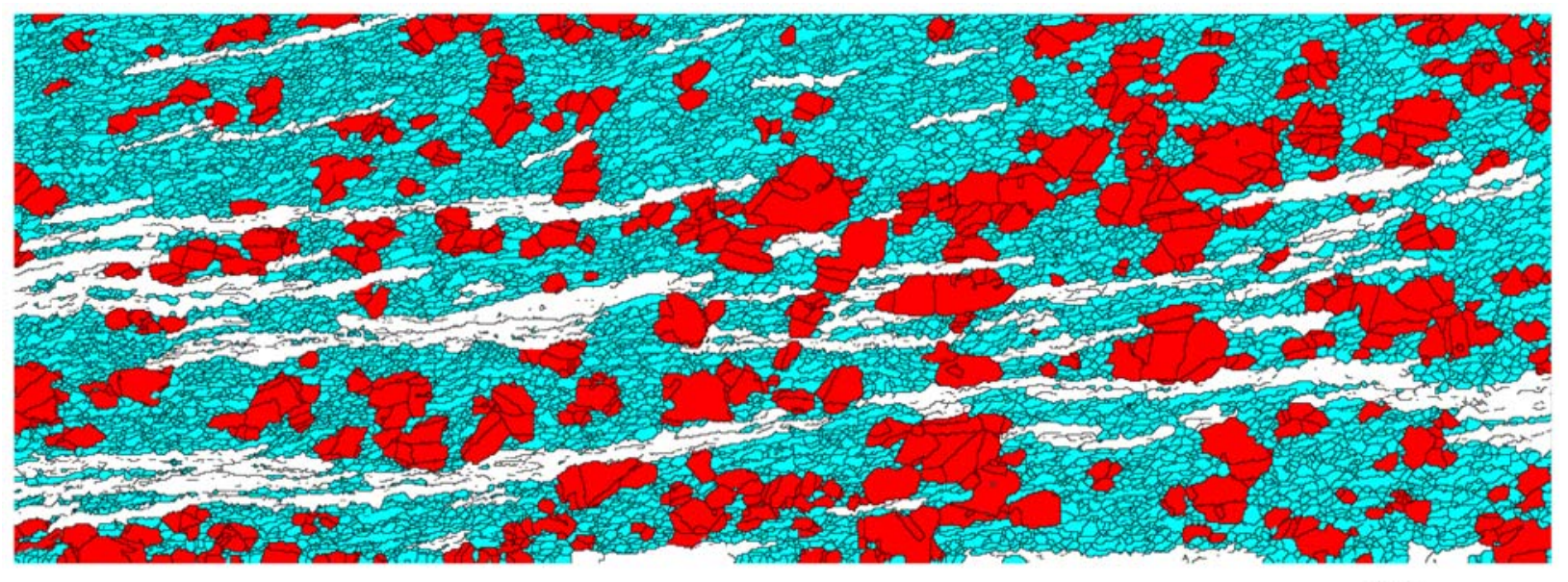

$10 \mu \mathrm{m}$

Fig. 2 LMR/HMR map for the center layer of the copper sample deformed to a strain of 10 via route A. LMRs are shown in white and HMRs are light grey (cyan in the online version). Recrystallized grains are shown in dark grey (red in the online version). Misorientations of $>5^{\circ}$ shown as black lines. Reproduced from [4] with kind permission of Springer Science and Business Media.

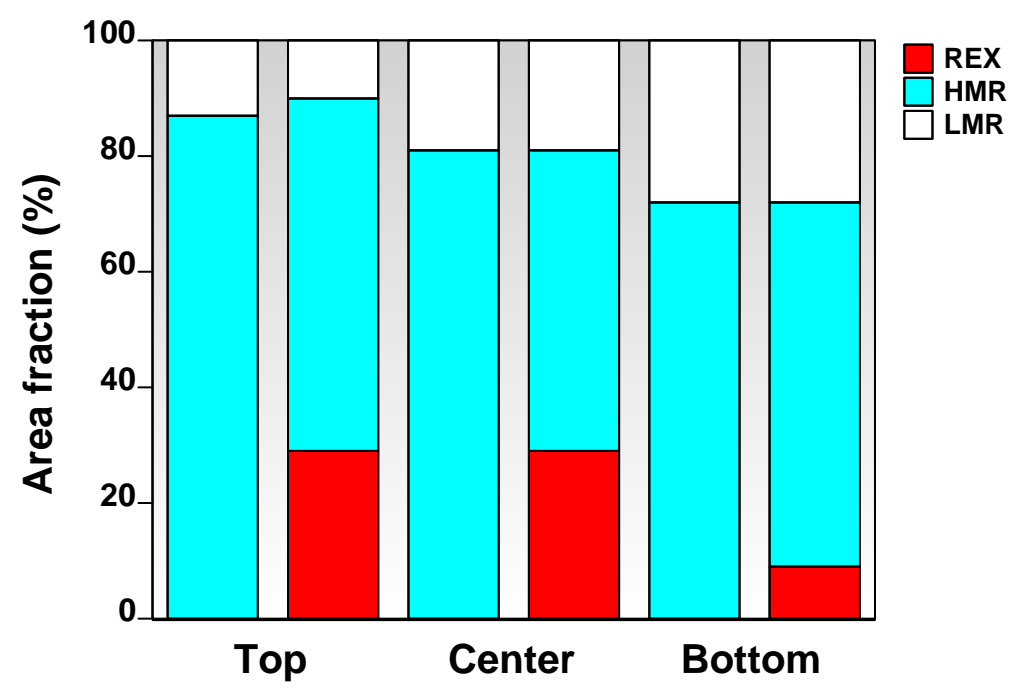

Fig. 3. Fractions of LMRs and HMRs in different layers of the copper billet deformed using route A ECAE to a strain of 10 and their relative loss due to partial recrystallization during $2 \mathrm{~h}$ annealing at $160^{\circ} \mathrm{C}$. For each layer the left hand bar corresponds to the proportion of the LMR and HMR areas in the extruded condition and the right hand bar shows the proportion of the HMR, LMR and recrystallized (REX) areas after the heat-treatment.

Comparing the extent of recrystallization in the three different layers, it is evident that it generally follows the distribution of strain. The less strained bottom part revealed larger HAB spacings than the other two layers, the lowest fraction of HABs and HMRs, and was less recrystallized than the other two layers (see Fig. 3). In the top and center layers, where the differences in the effective strain during deformation were small, and where the HAB fractions were similar (Table 1), the loss of the HMRs results in similar recrystallized fractions. 
Although the microstructure in pure copper processed by ECAE has been reported stable at temperatures below $100^{\circ} \mathrm{C}[1,9]$, we found evidence of partial recrystallization in the strain-8 samples stored at room temperature. Due to the lower strain, the HAB and HMR fractions were smaller in these samples than in the strain-10 sample (compare Table 1 and Table 2). However, the driving pressure in the strain-8 samples was sufficiently high to result in partial recrystallization at room temperature. Similar to the observations made after annealing, recrystallized grains produced during room-temperature storage were most frequently found in the HMRs (see Fig. 4). Quantitative EBSD analysis showed that recrystallized grains occupied 2-5\% of the total area inspected (Table 2). This and several other observations [10,11] prove that ECAE-processed copper is not stable at room temperature. A similar finding was recently obtained for ECAE-processed silver [12]. Heavily deformed pure metals of low to medium stacking fault energies are prone to room temperature recrystallization also when being subjected to other deformation modes [13,14]. In this respect, the ECAE-deformed microstructure is similar to other heavily deformed microstructures, where the high driving pressure and the presence of microstructural heterogeneities can trigger recrystallization even without additional heating.

Table 2. Microstructural characteristics in the center of two copper samples deformed using two different ECAE routes to a strain of $\sim 8$.

\begin{tabular}{lccccc}
\hline Sample & $\begin{array}{c}\text { Average HAB } \\
\text { spacing [ } \mu \mathrm{m}]\end{array}$ & HAB fraction [\%] & \multicolumn{3}{c}{ Area fraction [\%] } \\
\cline { 4 - 6 } & ND / ED & & HMRs & LMRs & REX \\
\hline $\mathrm{A}$ & $0.54 / 0.94$ & 46 & 60 & 38 & 2 \\
$\mathrm{Bc}$ & $0.78 / 1.20$ & 37 & 40 & 55 & 5 \\
\hline
\end{tabular}

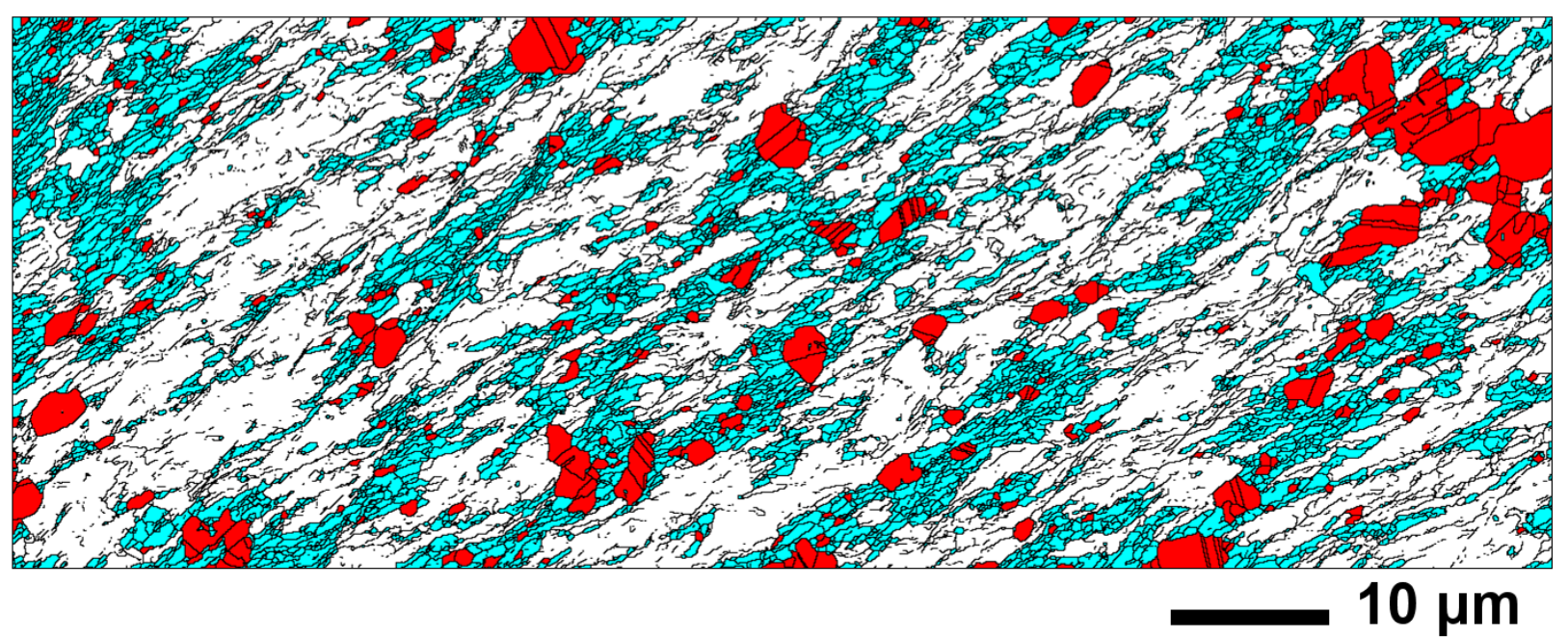

Fig. 4. LMR/HMR map for the center layer of the copper sample deformed using 8 ECAE passes via route Bc. LMRs are shown in white and HMRs are light grey (cyan in the online version). Misorientations of $>5^{\circ}$ shown as black lines. The dark grey (red in the online version) areas are small recrystallized grains observed in the microstructure after 8 years of room-temperature storage. Reproduced from [6] with kind permission of Springer Science and Business Media. 


\section{Summary}

Microstructures in the ECAE-processed copper samples are found to be heterogeneous. The extent of refinement by high angle boundaries is shown to vary both locally between different regions and between different layers. The presence of broad LMR bands in the heavily deformed microstructure appears to be related to their crystallographic orientation as such LMR bands frequently represented stable end orientations of the ECAE texture. On the sample scale, the area fraction of LMRs follows the distribution of strain being greater in the less strained bottom part of the billet. Reflecting the lower strain in this layer, recrystallization here was less pronounced than in the top and center layers. The HMRs are found to be preferable sites for nucleation during both controlled annealing and long-term room-temperature storage. Thus, the LMR/HMR partitioning provides a useful methodology to analyze heterogeneities in both deformed and annealed microstructures.

\section{Acknowledgements}

Financial support from the Danish National Research Foundation via the Center for Fundamental Research: Metal Structures in Four Dimensions is acknowledged.

\section{References}

[1] N.A. Akhmadeev, N.P. Kobelev, R.R. Mulyukov, Y.M. Soifer and R.Z. Valiev: Acta Metall. Mater., Vol. 41 (1993), p. 1041.

[2] S. Ferasse, V.M. Segal, K.T. Hartwig and R.E. Goforth: Metall. Mater. Trans A, Vol. 28A (1997), p.1047.

[3] J.R. Bowen, A. Gholinia, S.M. Roberts and P.B. Prangnell: Mater. Sci. Eng. A, Vol. 287 (2000), p. 87.

[4] O.V. Mishin and J.R. Bowen: Metall. Mater. Trans. A, Vol. 40A (2009), p. 1684.

[5] O.V. Mishin, D. Juul Jensen and N. Hansen: Mater. Sci. Eng. A, Vol. 342 (2003), p. 320.

[6] O.V. Mishin and A. Godfrey: Metall. Mater. Trans A, Vol. 39A (2008), p. 2923.

[7] O.V. Mishin, A. Godfrey and D. Juul Jensen, in: Electron Backscatter Diffraction in Materials Science, edited by A.J. Schwartz et al., Springer Science+Business Media, p. 263, DOI: 10.1007/978-0-387-88136-2_19.

[8] O.V. Mishin, J.R. Bowen and S. Lathabai: Scripta Mater., Vol. 63 (2010), p. 20.

[9] S. Komura, Z. Horita, M. Nemoto and T.G. Langdon: J. Mater. Res., Vol. 14 (1999), p. 4044.

[10] Y. Estrin, N.V. Isaev, S.V. Lubenets, S.V. Malykhin, A.T.Pugachov, V.V. Pustovalov, E.N. Reshetnyak, V.S. Fomenko, L.S. Fomenko, S.E. Shumilin, M. Janecek and R.J. Hellmig: Acta Mater., Vol. 54 (2006), p. 5581.

[11] A.L. Etter, T. Baudin, C. Rey and R. Penelle: Mater. Charact., Vol. 56 (2006), p. 19.

[12] J. Gubicza, N.Q. Chinh, J.L. Lábár, Z. Hegedus and T.G. Langdon: Mater. Sci. Eng. A, Vol. 527 (2010), p. 752.

[13] J. Schamp, B. Verlinden and J. Van Humbeeck: Scripta Mater., Vol. 34 (1996), p. 1667.

[14]T. Ichikawa, S. Aoyama, T. Takahashi and H. Nagayama: Hitachi Cable Rev., Vol. 19 (2000), p. 47. 